OPEN ACCESS

Edited by:

Yanqiang Li,

Harvard Medical School,

United States

Reviewed by:

Lin An,

Sanofi, United States

Shuo Zhang,

University of Pennsylvania,

United States

${ }^{*}$ Correspondence:

Jianmin Zhang

jzhang42@163.com

Specialty section:

This article was submitted to

Toxicogenomics,

a section of the journal

Frontiers in Genetics

Received: 06 October 2020

Accepted: 18 November 2020

Published: 08 December 2020

Citation:

Cai $M$, Zhang $X$, He W and

Zhang J (2020) The Involvement of

Metals in Alzheimer's Disease

Through Epigenetic Mechanisms.

Front. Genet. 11:614666.

doi: 10.3389/fgene.2020.614666

\section{The Involvement of Metals in Alzheimer's Disease Through Epigenetic Mechanisms}

\author{
Menghua Cai, Xiangjin Zhang, Wei He and Jianmin Zhang*
}

State Key Laboratory of Medical Molecular Biology, Department of Immunology, Institute of Basic Medical Sciences, Chinese Academy of Medical Sciences, Beijing, China

Alzheimer's disease (AD) is the most frequent cause of dementia among neurodegenerative diseases. Two factors were hypothesized to be involved in the pathogenesis of AD, namely beta-amyloid cascade and tauopathy. At present, accumulating evidence suggest that epigenetics may be the missing linkage between genes and environment factors, providing possible clues to understand the etiology of the development of $A D$. In this article, we focus on DNA methylation and histone modification involved in $A D$ and the environment factor of heavy metals' contribution to $A D$, especially epigenetic mechanisms. If we can integrate information together, and that may find new potential targets for the treatment.

Keywords: Alzheimer's disease, DNA methylation, histone modifications, metals, demenita

\section{INTRODUCTION}

Neurodegenerative disorders are characterized by the progressive accumulation of misfolded proteins, which trigger damage of synapses, disturb network of pathway, facilitate death of specific neuronal populations, and finally initiate diseases. Several factors were hypothesized to be associated with the etiology of those diseases, including genetic and environmental factors. Alzheimer's disease (AD) is the most common neurodegenerative disease, and the hallmarks of $\mathrm{AD}$ pathology are an accumulation of $\mathrm{A} \beta$ to form amyloid-plaques and aggregation of phosphorylated tau to constitute neurofibrillary tangles (NFTs). A $\beta$ is viewed as the core stone and trigger of diseases, which induces the dysfunction of synapses, loss of neurons, and ultimately dementia, with the existence of A $\beta$ plaques and NTFs (Morris et al., 2014). Hyperphosphorylation changed the conformation of tau, which was believed to play a role in synaptic plasticity and facilitated its misfolding in pathological process (Zhang et al., 2016). Beside, apolipoprotein $\mathrm{E}(A p o E)$ gene shows strong association with risk for $\mathrm{AD}$, for ApoE combined directly with $A \beta$ to promote its aggregation and that facilitated tau phosphorylation inducing NFTs (Brecht et al., 2004).

Epigenetics is the study of heritable and reversible changes in gene expression, including DNA methylation, multi-modification of histones, and microRNA (Collotta et al., 2013), which occur without a change in the DNA sequence. This article reviewed DNA methylation and histone modifications to exhibit latest understanding about the role epigenetics plays in AD. 


\section{DNA Methylation}

The first report epigenetic changes in $\mathrm{AD}$ found hypomethylation of amyloid precursor protein (APP) from an $\mathrm{AD}$ patient (West et al., 1995). In a pair of monozygotic twins, levels of DNA methylation significantly decreased in temporal neocortex neuronal nuclei of the AD twin (Mastroeni et al., 2009). Besides, DNA methyltransferase (DNMT) decreased in entorhinal cortex layer II of AD patients (Mastroeni et al., 2010). In a recent research, the patient group showed 25\% reduction of DNA methylation levels in mitochondrial DNA D-loop region (Stoccoro et al., 2017), suggesting the underlying role of mitochondrial DNA methylation in $\mathrm{AD}$. Hypomethylation of BRCA1 was observed in $\mathrm{AD}$ patients, and this result was in consistent with the higher expression of its mRNA (Mano et al., 2017). Through comparing brains of mouse models and $\mathrm{AD}$ patients, hyper-methylation of three genes namely TBXA2R, SPTBN4, and SORBS3 resulted in silence of these genes in AD process (Sanchez-Mut et al., 2013).

\section{Histone Modification}

Comparing the temporal cortex and hippocampus, the twin with $\mathrm{AD}$ showed a significantly higher level of H3K9me3, a sign of gene silence, and $\mathrm{H} 3 \mathrm{~S} 10$ phosphorylation, a regulator of chromatin structure (Wang et al., 2013). The brains from $\mathrm{AD}$ patients showed hyper-acetylation in histone $\mathrm{H} 3$ and $\mathrm{H} 4$ (Narayan et al., 2015). Histone deacetylation catalyzed by histone deacetylase (HDAC) results in a condensed state of chromatin and consequent transcriptional repression. HDAC2 increased in $\mathrm{AD}$-related neurotoxic insults in vitro, two mouse models and patients with $\mathrm{AD}$, which decreased the histone acetylation of genes related to memory and inhibited their expression (Graff et al., 2012). Tau interacts with HDAC6 to decrease its activity. Through this way, tau promoted the acetylation of related genes (Perez et al., 2009). As a feedback and compensation, the expression of HDAC6 was significantly increased. In a mouse model of $\mathrm{AD}$, decreased HDAC6 facilitated the recovery of learning and memory through disturbing mitochondrial trafficking dysfunction caused by A $\beta$ (Govindarajan et al., 2013). Importantly, the $\mathrm{AD}$ mouse model treatment with valproic acid (VPA), one of widely used HDAC inhibitors in clinical research, has shown exciting results. VPA significantly decreased A $\beta$ production by inhibiting $\gamma$-secretase cleavage of APP and alleviated the memory deficits of the AD mice (Qing et al., 2008).

\section{Roles of Metals in AD Plumbum}

Plumbum facilitated the concentrations of free radicals, which leaded to the death of neurons. $\mathrm{Pb}$ exposure stimulated the serine/threonine phosphatases to impair memory formation (Rahman et al., 2011). Pb exposure leaded to the DNA methylation changes in the whole blood cells (Hanna et al., 2012). Early exposure of $\mathrm{Pb}$ increased $\mathrm{A} \beta$ product in old age. While in aged monkeys exposed to $\mathrm{Pb}$ as infants, the expression of APP and BACE1 elevated, and the activity of DNMT decreased (Wu et al., 2008). In rodents exposed lead, the expression of APP increased 20 months later, implying that lead exposure showed a life-long risk of AD (Basha et al., 2005).
In mice model of $\mathrm{AD}$ exposure to $\mathrm{Pb}$, the levels of $\mathrm{DNMT} 1$, $\mathrm{H} 3 \mathrm{~K} 9 \mathrm{ac}$, and $\mathrm{H} 3 \mathrm{~K} 4 \mathrm{me} 2$ decreased, the level of $\mathrm{H} 3 \mathrm{~K} 27 \mathrm{me} 3$ increased, while the concentration of DNMT3a did not change (Eid et al., 2016). Besides, $\mathrm{Pb}$ exposure altered the production of tau (Dash et al., 2016). In mice expressing human APP, $\mathrm{Pb}$ stimulated the production of $\mathrm{A} \beta$ ( $\mathrm{Gu}$ et al., 2011). $\mathrm{Pb}$ also disturbed the clearance of $\mathrm{A} \beta$ plaques by suppressing the activity of neprilysin (Huang et al., 2011). In primates with early exposure of $\mathrm{Pb}$, their brains showed overexpression of APP and A $\beta$ through hypo-methylation of related genes when aging. Yegambaram also reported that early exposure of $\mathrm{Pb}$ leaded to overexpression of APP, BACE1, and PS1, one of their regulators (Yegambaram et al., 2015). Both of them suggest that early exposure of $\mathrm{Pb}$ played a role in the development of $\mathrm{AD}$ when aging.

\section{Arsenic}

S-adenosyl-methionine (SAM) is essential for methylation of inorganic arsenic to detoxication, and it is also the metyl-donor required by DNA methyltransferases. So, it is reasonable to speculate that arsenic exposure leads to hypo-methylation of DNA and facilitates tumor-related gene expression (Zhao et al., 1997). Insufficiency of SAM leaded to hypomethylation of PS1 and $B A C E$ genes. This hypomethylation increased the expression of PS1 and BACE, which facilitated the production of $A \beta$ (Fuso et al., 2005). Besides, arsenic inhibited the expression of the DNA methyltransferase genes, DNMT1 and DNMT3a (Reichard et al., 2007). Sodium arsenite exposure inhibited HDAC p300 for attenuating $\mathrm{H} 3 \mathrm{~K} 27 \mathrm{ac}$ at enhancers in mouse embryonic fibroblast cells (Zhu et al., 2018). Su reported a dose-response relationship between the environmental concentration of total arsenic in topsoils and the prevalence and mortality of $\mathrm{AD}$ in European countries (Yegambaram et al., 2015).

Environmental toxin arsenite induced a remarked increase in the phosphorylation of several sits in tau, including Thr-181, Ser-202, Thr-205, Thr-231, Ser-262, Ser-356, Ser-396, and Ser-404, which was in coincidence with results from AD (Giasson et al., 2002). Gong argued that arsenic stimulated the generation of free radicals, which leaded to oxidative stress and neuronal death (Gong and O'Bryant, 2010). When mothers were exposed to arsenic during pregnancy, their children showed a higher activation of inflammation-related pathways involved in the development of AD (Fry et al., 2007).

\section{Aluminum}

Aluminum has been reported to induce neurofibrillary degeneration in neurons of higher mammals in 1970s (Crapper et al., 1973). McLachlan reported a dose-effect association between the risk of $\mathrm{AD}$ and residual aluminum in municipal drinking water. The estimated relative risk of $\mathrm{AD}$ for residents with drinking water containing more than $100 \mathrm{ug} / \mathrm{L}$ of $\mathrm{Al}$ was 1.7 (McLachlan et al., 1996). Walton (2014) reported that long term intake of $\mathrm{Al}$ was an etiology of $\mathrm{AD}$. A 15-year follow-up implemented by Rondeau et al. (2009) also showed a significant association between a high daily intake of aluminum and increased risk of dementia. Al could selectively interact with $\mathrm{A} \beta$ to facilitate the formation of fibrillar aggregation, while copper, iron, or zinc could not (Bolognin et al., 2011). 
In transgenic mice overexpressed human APP (Tg2576), dietary $\mathrm{Al}$ stimulated the expression and aggregation of $\mathrm{A} \beta$ through increasing oxidative stress (Pratico et al., 2002). In embryo rat hippocampal neurons, high concentration of $\mathrm{Al}$ facilitated the production of ROS induced by Fe (Xie et al., 1996). Al facilitated the degradation from APP to the aggregation of $A \beta$ (Kawahara et al., 1994). Besides, the structure of non-A $\beta$ component of $\mathrm{AD}$ amyloid was changed by the induction of Al to resist degradation and form plaque (Paik et al., 1997).

\section{CONCLUSION}

No mutation in genes has been definitely associated with neurodegenerative diseases, suggesting that, besides risk factors of gene, environmental exposure also is involved in the etiology of $\mathrm{AD}$, and those two factors may be abridged through epigenetic alterations. Recently, an integrated multiomics analyses identified molecular pathways associated with $\mathrm{AD}$ and revealed the $\mathrm{H} 3$ modifications $\mathrm{H} 3 \mathrm{~K} 27 \mathrm{ac}$ and $\mathrm{H} 3 \mathrm{~K} 9 \mathrm{ac}$ as potential epigenetic drivers linked to transcription and chromatin and disease pathways in AD (Nativio et al., 2020). These findings provide mechanistic insights on $\mathrm{AD}$ for aiming

\section{REFERENCES}

Basha, M. R., Wei, W., Bakheet, S. A., Benitez, N., Siddiqi, H. K., Ge, Y. W., et al. (2005). The fetal basis of amyloidogenesis: exposure to lead and latent overexpression of amyloid precursor protein and beta-amyloid in the aging brain. J. Neurosci. 25, 823-829. doi: 10.1523/JNEUROSCI.4335-04.2005

Bolognin, S., Messori, L., Drago, D., Gabbiani, C., Cendron, L., and Zatta, P. (2011). Aluminum, copper, iron and zinc differentially alter amyloid-A $\beta(1-42)$ aggregation and toxicity. Int. J. Biochem. Cell Biol. 43, 877-885. doi: 10.1016/j. biocel.2011.02.009

Brecht, W. J., Harris, F. M., Chang, S., Tesseur, I., Yu, G. Q., Xu, Q., et al. (2004). Neuron-specific apolipoprotein e4 proteolysis is associated with increased tau phosphorylation in brains of transgenic mice. J. Neurosci. 24, 2527-2534. doi: 10.1523/JNEUROSCI.4315-03.2004

Collotta, M., Bertazzi, P. A., and Bollati, V. (2013). Epigenetics and pesticides. Toxicology 307, 35-41. doi: 10.1016/j.tox.2013.01.017

Crapper, D. R., Krishnan, S. S., and Dalton, A. J. (1973). Brain aluminum distribution in Alzheimer's disease and experimental neurofibrillary degeneration. Science 180, 511-513. doi: 10.1126/science.180.4085.511

Dash, M., Eid, A., Subaiea, G., Chang, J., Deeb, R., Masoud, A., et al. (2016). Developmental exposure to lead $(\mathrm{Pb})$ alters the expression of the human tau gene and its products in a transgenic animal model. Neurotoxicology 55, 154-159. doi: 10.1016/j.neuro.2016.06.001

Eid, A., Bihaqi, S. W., Renehan, W. E., and Zawia, N. H. (2016). Developmental lead exposure and lifespan alterations in epigenetic regulators and their correspondence to biomarkers of Alzheimer's disease. Alzheimers Dement. 2, 123-131. doi: 10.1016/j.dadm.2016.02.002

Fry, R. C., Navasumrit, P., Valiathan, C., Svensson, J. P., Hogan, B. J., Luo, M., et al. (2007). Activation of inflammation/NF-kappaB signaling in infants born to arsenic-exposed mothers. PLoS Genet. 3:e207. doi: 10.1371/journal. pgen.0030207

Fuso, A., Seminara, L., Cavallaro, R. A., D’Anselmi, F., and Scarpa, S. (2005). S-adenosylmethionine/homocysteine cycle alterations modify DNA methylation status with consequent deregulation of PS1 and BACE and beta-amyloid production. Mol. Cell. Neurosci. 28, 195-204. doi: 10.1016/j. men.2004.09.007

Giasson, B. I., Sampathu, D. M., Wilson, C. A., Vogelsberg-Ragaglia, V., Mushynski, W. E., and Lee, V. M. (2002). The environmental toxin arsenite epigenetic regulation of therapeutic strategy. We should get more enlightenment from it and explore the relationship between $\mathrm{AD}$ and epigenetics. On this basis, we will further study the effective diagnosis, treatment, and prevention methods of $\mathrm{AD}$, and develop new intervention measures for $\mathrm{AD}$ from the field of epigenetics.

\section{AUTHOR CONTRIBUTIONS}

MC wrote the manuscript. XZ helped to edit the manuscript. $\mathrm{WH}$ and JZ revised the manuscript. All authors contributed to the article and approved the submitted version.

\section{FUNDING}

This work was supported by the National Natural Science Foundation of China (31471016), the National Key Research and Development Program of China (2016YFA0101001), the CAMS Initiative for Innovative Medicine (2016-I2M-1-008), and CAMS Central Public Welfare Scientific Research Institute Basal Research Expenses (2018PT32004).

induces tau hyperphosphorylation. Biochemistry 41, 15376-15387. doi: 10.1021/ bi026813c

Gong, G., and O'Bryant, S. E. (2010). The arsenic exposure hypothesis for Alzheimer disease. Alzheimer Dis. Assoc. Disord. 24, 311-316. doi: 10.1097/ WAD.0b013e3181d71bc7

Govindarajan, N., Rao, P., Burkhardt, S., Sananbenesi, F., Schluter, O. M., Bradke, F., et al. (2013). Reducing HDAC6 ameliorates cognitive deficits in a mouse model for Alzheimer's disease. EMBO Mol. Med. 5, 52-63. doi: 10.1002/emmm.201201923

Graff, J., Rei, D., Guan, J. S., Wang, W. Y., Seo, J., Hennig, K. M., et al. (2012). An epigenetic blockade of cognitive functions in the neurodegenerating brain. Nature 483, 222-226. doi: 10.1038/nature10849

Gu, H., Wei, X., Monnot, A. D., Fontanilla, C. V., Behl, M., Farlow, M. R., et al. (2011). Lead exposure increases levels of $\beta$-amyloid in the brain and CSF and inhibits LRP1 expression in APP transgenic mice. Neurosci. Lett. 490, 16-20. doi: 10.1016/j.neulet.2010.12.017

Hanna, C. W., Bloom, M. S., Robinson, W. P., Kim, D., Parsons, P. J., vom Saal, F. S., et al. (2012). DNA methylation changes in whole blood is associated with exposure to the environmental contaminants, mercury, lead, cadmium and bisphenol A, in women undergoing ovarian stimulation for IVF. Hum. Reprod. 27, 1401-1410. doi: 10.1093/humrep/des038

Huang, H., Bihaqi, S. W., Cui, L., and Zawia, N. H. (2011). In vitro Pb exposure disturbs the balance between $\mathrm{A} \beta$ production and elimination: the role of A $\beta$ PP and neprilysin. Neurotoxicology 32, 300-306. doi: 10.1016/j. neuro.2011.02.001

Kawahara, M., Muramoto, K., Kobayashi, K., Mori, H., and Kuroda, Y. (1994). Aluminum promotes the aggregation of Alzheimer's amyloid beta-protein in vitro. Biochem. Biophys. Res. Commun. 198, 531-535. doi: 10.1006/ bbrc.1994.1078

Mano, T., Nagata, K., Nonaka, T., Tarutani, A., Imamura, T., Hashimoto, T., et al. (2017). Neuron-specific methylome analysis reveals epigenetic regulation and tau-related dysfunction of BRCA1 in Alzheimer's disease. Proc. Natl. Acad. Sci. U. S. A. 114, E9645-E9654. doi: 10.1073/pnas. 1707151114

Mastroeni, D., Grover, A., Delvaux, E., Whiteside, C., Coleman, P. D., and Rogers, J. (2010). Epigenetic changes in Alzheimer's disease: decrements in DNA methylation. Neurobiol. Aging 31, 2025-2037. doi: 10.1016/j. neurobiolaging.2008.12.005 
Mastroeni, D., McKee, A., Grover, A., Rogers, J., and Coleman, P. D. (2009). Epigenetic differences in cortical neurons from a pair of monozygotic twins discordant for Alzheimer's disease. PLoS One 4:e6617. doi: 10.1371/journal. pone. 0006617

McLachlan, D. R., Bergeron, C., Smith, J. E., Boomer, D., and Rifat, S. L. (1996). Risk for neuropathologically confirmed Alzheimer's disease and residual aluminum in municipal drinking water employing weighted residential histories. Neurology 46, 401-405. doi: 10.1212/wnl.46.2.401

Morris, G. P., Clark, I. A., and Vissel, B. (2014). Inconsistencies and controversies surrounding the amyloid hypothesis of Alzheimer's disease. Acta Neuropathol. Commun. 2:135. doi: 10.1186/s40478-014-0135-5

Narayan, P. J., Lill, C., Faull, R., Curtis, M. A., and Dragunow, M. (2015). Increased acetyl and total histone levels in post-mortem Alzheimer's disease brain. Neurobiol. Dis. 74, 281-294. doi: 10.1016/j.nbd.2014.11.023

Nativio, R., Lan, Y., Donahue, G., Sidoli, S., Berson, A., Srinivasan, A. R., et al. (2020). An integrated multi-omics approach identifies epigenetic alterations associated with Alzheimer's disease. Nat. Genet. 52, 1024-1035. doi: 10.1038/s41588-020-0696-0

Paik, S. R., Lee, J. H., Kim, D. H., Chang, C. S., and Kim, J. (1997). Aluminuminduced structural alterations of the precursor of the non-A beta component of Alzheimer's disease amyloid. Arch. Biochem. Biophys. 344, 325-334. doi: 10.1006/abbi.1997.0207

Perez, M., Santa-Maria, I., Gomez de Barreda, E., Zhu, X., Cuadros, R., Cabrero, J. R., et al. (2009). Tau--an inhibitor of deacetylase HDAC6 function. J. Neurochem. 109, 1756-1766. doi: 10.1111/j.1471-4159.2009.06102.x

Pratico, D., Uryu, K., Sung, S., Tang, S., Trojanowski, J. Q., and Lee, V. M. (2002). Aluminum modulates brain amyloidosis through oxidative stress in APP transgenic mice. FASEB J. 16, 1138-1140. doi: 10.1096/fj.02-0012fje

Qing, H., He, G., Ly, P. T., Fox, C. J., Staufenbiel, M., Cai, F., et al. (2008). Valproic acid inhibits Abeta production, neuritic plaque formation, and behavioral deficits in Alzheimer's disease mouse models. J. Exp. Med. 205, 2781-2789. doi: 10.1084/jem.20081588

Rahman, A., Brew, B. J., and Guillemin, G. J. (2011). Lead dysregulates serine/ threonine protein phosphatases in human neurons. Neurochem. Res. 36, 195-204. doi: 10.1007/s11064-010-0300-6

Reichard, J. F., Schnekenburger, M., and Puga, A. (2007). Long term low-dose arsenic exposure induces loss of DNA methylation. Biochem. Biophys. Res. Commun. 352, 188-192. doi: 10.1016/j.bbrc.2006.11.001

Rondeau, V., Jacqmin-Gadda, H., Commenges, D., Helmer, C., and Dartigues, J. F. (2009). Aluminum and silica in drinking water and the risk of Alzheimer's disease or cognitive decline: findings from 15-year follow-up of the PAQUID cohort. Am. J. Epidemiol. 169, 489-496. doi: 10.1093/aje/kwn348

Sanchez-Mut, J. V., Aso, E., Panayotis, N., Lott, I., Dierssen, M., Rabano, A., et al. (2013). DNA methylation map of mouse and human brain identifies target genes in Alzheimer's disease. Brain 136, 3018-3027. doi: 10.1093/ brain/awt 237
Stoccoro, A., Siciliano, G., Migliore, L., and Coppede, F. (2017). Decreased methylation of the mitochondrial D-loop region in late-onset Alzheimer's disease. J. Alzheimers Dis. 59, 559-564. doi: 10.3233/JAD-170139

Walton, J. R. (2014). Chronic aluminum intake causes Alzheimer's disease: applying Sir Austin Bradford Hill's causality criteria. J. Alzheimers Dis. 40, 765-838. doi: 10.3233/JAD-132204

Wang, J., Yu, J. T., Tan, M. S., Jiang, T., and Tan, L. (2013). Epigenetic mechanisms in Alzheimer's disease: implications for pathogenesis and therapy. Ageing Res. Rev. 12, 1024-1041. doi: 10.1016/j.arr.2013.05.003

West, R. L., Lee, J. M., and Maroun, L. E. (1995). Hypomethylation of the amyloid precursor protein gene in the brain of an Alzheimer's disease patient. J. Mol. Neurosci. 6, 141-146. doi: 10.1007/BF02736773

Wu, J., Basha, M. R., Brock, B., Cox, D. P., Cardozo-Pelaez, F., McPherson, C. A., et al. (2008). Alzheimer's disease (AD)-like pathology in aged monkeys after infantile exposure to environmental metal lead $(\mathrm{Pb})$ : evidence for a developmental origin and environmental link for AD. J. Neurosci. 28, 3-9. doi: 10.1523/JNEUROSCI.4405-07.2008

Xie, C. X., Mattson, M. P., Lovell, M. A., and Yokel, R. A. (1996). Intraneuronal aluminum potentiates iron-induced oxidative stress in cultured rat hippocampal neurons. Brain Res. 743, 271-277. doi: 10.1016/s0006-8993(96)01055-4

Yegambaram, M., Manivannan, B., Beach, T. G., and Halden, R. U. (2015). Role of environmental contaminants in the etiology of Alzheimer's disease: a review. Curr. Alzheimer Res. 12, 116-146. doi: 10.2174/1567205012666150204121719

Zhang, C. C., Xing, A., Tan, M. S., Tan, L., and Yu, J. T. (2016). The role of MAPT in neurodegenerative diseases: genetics, mechanisms and therapy. Mol. Neurobiol. 53, 4893-4904. doi: 10.1007/s12035-015-9415-8

Zhao, C. Q., Young, M. R., Diwan, B. A., Coogan, T. P., and Waalkes, M. P. (1997). Association of arsenic-induced malignant transformation with DNA hypomethylation and aberrant gene expression. Proc. Natl. Acad. Sci. U. S. A. 94, 10907-10912. doi: 10.1073/pnas.94.20.10907

Zhu, Y., Li, Y., Lou, D., Gao, Y., Yu, J., Kong, D., et al. (2018). Sodium arsenite exposure inhibits histone acetyltransferase p300 for attenuating $\mathrm{H} 3 \mathrm{~K} 27 \mathrm{ac}$ at enhancers in mouse embryonic fibroblast cells. Toxicol. Appl. Pharmacol. 357, 70-79. doi: 10.1016/j.taap.2018.08.011

Conflict of Interest: The authors declare that the research was conducted in the absence of any commercial or financial relationships that could be construed as a potential conflict of interest.

Copyright (C) 2020 Cai, Zhang, He and Zhang. This is an open-access article distributed under the terms of the Creative Commons Attribution License (CC BY). The use, distribution or reproduction in other forums is permitted, provided the original author(s) and the copyright owner(s) are credited and that the original publication in this journal is cited, in accordance with accepted academic practice. No use, distribution or reproduction is permitted which does not comply with these terms. 